\title{
Experience of the Time to Change programme in England as predictor of mental health service users' stigma coping strategies
}

\author{
G. Sampogna $^{1 *}$, I. Bakolis ${ }^{2,3}$, E. Robinson ${ }^{3}$, E. Corker ${ }^{4}$, V. Pinfold ${ }^{5}$, G. Thornicroft ${ }^{2}$ and C. Henderson ${ }^{2}$ \\ ${ }^{1}$ Department of Psychiatry, University of Naples SUN, Naples, Italy \\ ${ }^{2}$ Health Services and Population Research Department, Institute of Psychiatry, Psychology and Neuroscience, King's College London, London, UK \\ ${ }^{3}$ Department of Biostatistics, Institute of Psychiatry, Psychology and Neuroscience, King's College London, London, UK \\ ${ }^{4}$ Unit for Social and Community Psychiatry, WHO Collaborative Centre for Mental Health, London E13 8SP H, UK \\ ${ }^{5}$ McPin Foundation, 32-36 Loman Street, London SE1 OE, UK
}

Aims. In the field of stigma research, an area of interest is the coping strategies that mental health service users can use in response to discriminatory experiences. As a part of the evaluation of the Time to Change (TTC) anti-stigma programme, the Viewpoint telephone survey was run annually in order to assess service users' reported levels of discrimination and selected coping strategies. The study aim is to test the extent to which experience of TTC programme is a positive predictor of selected coping strategies.

Methods. Telephone interview surveys carried out by peer interviewers were conducted annually. 'Educating others' and 'challenging' coping strategies were assessed alongside anticipated and experienced discrimination.

Results. During 2011-2014, 3903 mental health service users were interviewed. Participants more often adopted the 'educating others' strategy $(2.31 \pm 0.01)$ than the 'challenging' strategy $(2.15 \pm 0.02)(p<0.001)$. On the other hand, those who participated in campaign activities endorsed 'challenging' more frequently than people who were not aware of TTC $(2.78 \pm 1.23$ v. $2.09 \pm 1.08, p<0.001)$. According to the multi-variate linear regression model, we found that being actively involved in TTC activities (OR $=0.74, \mathrm{CI}: 0.29-1.19 ; p<0.05)$, having a diagnosis of a depressive disorder $(\mathrm{OR}=0.20$, CI: $0.04-0.36 ; p<0.05)$ or personality disorder $(\mathrm{OR}=0.23, \mathrm{CI}: 0.04-0.43 ; p<0.05)$ were good predictors of endorsing a 'challenging' strategy even after adjusted for confounding variables.

Conclusions. A positive relationship between participating in the TTC programme and using the 'challenging' strategy was found. There is still a need to disentangle the complex association between these two coping strategies and the role of anti-stigma campaigns, promoting further local activities led by service users and carers' as well as all others stakeholders' associations.

Received 8 April 2016; Accepted 29 May 2016; First published online 28 July 2016

Key words: Coping strategy, discrimination, mental health, public health, stigma.

\section{Introduction}

It has been well documented that people with mental health problems report high levels of discrimination (Sibitz et al. 2011; Evans-Lacko et al. 2012; Farrelly et al. 2014; Griffiths et al. 2014). There is an increasing effort to try to end discrimination towards people affected by mental health problems (Heinz et al. 2015; Mehta et al. 2015; Thornicroft et al. 2015; Wahlbeck, 2015; Weissman, 2015), with the promotion of antistigma programmes worldwide such as 'Like Minds,

* Address for correspondence: G. Sampogna, Department of Psychiatry, University of Naples SUN, Largo Madonna delle Grazie, 80138 Naples, Italy.

(Email: gaia.sampogna@gmail.com)
Like Mine' (Vaughan \& Hansen, 2004; Thornicroft et al. 2014), 'Opening Minds' (Sartorius, 2014; Stuart et al. 2014), and 'Open the Doors' (Rüsch et al. 2005; Gaebel et al. 2008; NHS Scotland, 2008; Thornicroft et al. 2008; Evans-Lacko et al. 2012; Evans-Lacko et al. 2014a, b).

The Time to Change (TTC) anti-stigma programme, England's largest programme aimed at reducing stigma and discrimination against people with mental health problems, started in 2007 (http://www.timeto-change.org.uk/) (Henderson et al. 2013). One of the main strategies of the TTC programme was to encourage service user leadership including events with the active involvement of mental health service users (i.e. 'Get moving', 'Living libraries' and 'Education not discrimination' activities) (Evans-Lacko et al. 2013; Friedrich et al. 2013). As part of the evaluation of

This is an Open Access article, distributed under the terms of the Creative Commons Attribution licence (http://creativecommons.org/licenses/by/4.0/), which permits unrestricted re-use, distribution, and reproduction in any medium, provided the original work is properly cited. 
TTC, and specifically to assess the effect of the programme on people with mental health problems, the Viewpoint survey was run annually to assess individuals' experience of discrimination within the previous 12 months (Henderson \& Thornicroft, 2009; Henderson et al. 2012; Corker et al. 2013; Evans-Lacko, 2014a). Moreover, in the field of overcoming discrimination, it is important to assess service users' responses to discriminatory experiences, which constitute the process of coping (Mendoza-Denton et al. 2006; Hinshaw, 2007). Coping strategies may represent a way for service users to reduce the level of discrimination they experience (Farrelly et al. 2015).

According to Stuart et al. (2012), the most important contribution to the conceptualization and measurement of stigma coping is the work by Link et al. (2001). Link distinguished several coping orientations: 'secrecy', described as concealing labelling information; 'education', consisting in providing information to counter stereotypes; 'withdrawal', defined as avoiding potential rejecting situations; 'distancing', cognitive separation of the potentially stigmatised person from the stigmatised group; and 'challenging', active confrontation of stigmatising behaviour (Link et al. 2014). The TTC programme aims to enhance the 'challenging' and 'educating' strategies in people with mental health problems. Since 2011, to provide a baseline for the second phase of the TTC programme - which began in October 2011 - questions on coping with stigma based on Link et al. conceptualization (1991, 2002) were added.

Coping strategies are far from being uniform among mental health service users. Research has found their endorsement is influenced by socio-demographic characteristics, variables related to mental health problems, and by the person's social functioning (Major \& Townsend, 2010; Moses, 2015).

To the best of our knowledge, no previous studies have evaluated whether anti-stigma programmes are possible predictors of coping strategies adopted by people with mental health problems.

Our primary hypothesis was that having actively participated in programme activities would be more strongly associated with the use of both 'challenging' and 'educating' coping strategies, than just having seeing some of the social marketing campaign, as the programme seeks to both educate and challenge.

\section{Methods}

From 2008 to 2014, telephone interview surveys (the Viewpoint survey) were conducted annually. Each year, five National Health Service (NHS) mental health trusts across England were selected to take part.
Different trusts and/or different regions within the same trusts were selected each year. Participants were recruited through NHS mental health trusts (service provider organisations). The target sample was 1000 individual interviews in each year. The inclusion criteria were: age between 18 and 65 years; having a diagnosis of any mental disorder; being in contact with the specialist mental health services in the previous 6 months. Patients who were not currently living in the community (e.g., were in prison or hospital) were excluded as well as patients with a diagnosis of dementia. A specific part of the Viewpoint survey was the use of interviewers with lived experience of mental health problems (Hamilton et al. 2011). Telephone interviewers were trained and supervised by members of the research team. Allocation of participants to interviewers was based on interviewer availability. The detailed methodology is reported elsewhere (Hamilton et al. 2011; Corker et al. 2013; Henderson et al. 2014).

\section{Assessment tools}

The primary outcome of the study was to assess the possible predictive role of participation in the TTC programme on mental health users' reported coping strategies as per Link et al. (2002). Coping strategies were assessed through a modified version of the scale developed by Link et al. (2002). According to the main characteristics of the TTC programme, based on the active involvement and participation of people with mental health problems, the 'challenging' and 'educating' coping strategies were evaluated (Henderson et al. 2013). The 'challenging' strategy is defined as people's orientation to confronting prejudice and discrimination. It assesses how likely respondents are to challenge stigmatising behaviour when it occurs or to disagree with people who make stigmatising statements. Items are scored on a 5-level Likert scale, ranging from $1=$ never to $5=$ often. The global score of the scale is the mean of five items, with higher score indicating higher endorsement of the strategy. The 'educating' strategy is described as the respondents' orientation to educating others in order to reduce the possibility of rejection. This subscale comprises three items, each item ranges on a 4-level Likert score, from $1=$ strongly agree to $4=$ strongly disagree. The global score of the scale is the mean of three items, with higher scores indicating higher level of experience of using this strategy. As suggested by Link et al. (2002), the 2.5 midpoint of each subscale was considered as cut-off for evaluating whether the coping strategy was used or not.

Regarding the evaluation of the experience of the TTC programme, participants were asked a question, 
which had three possible answers: have seen some publicity; have participated in some activities; or have not seen any publicity of TTC programme. This variable was managed as a categorical variable, considering 'have not seen any publicity of TTC programme' as the reference category.

The Discrimination and Stigma Scale (DISC-12) was used to measure both experienced and anticipated discrimination (Brohan et al. 2013). The DISC was administered by the interviewer by telephone. It consists of 22 items on negative, mental health-related experiences of discrimination (covering 21 specific life areas, plus one for 'other' experience) and four items concerning anticipated discrimination. Each item is scored on a 4-point scale from 'not at all' to 'a lot'.

The Resource Generator-UK (RG-UK) was used to evaluate the participant's access to social resources, a method of measuring social capital (Webber \& Huxley, 2007). Social capital is defined as available resources accessible to the person through trusting and reciprocal relationships within the social networks (Henderson et al. 2014). The RG-UK evaluates the capacity of participants to obtain access to several skills and resources within their social network within 1 week, if they needed it. The items are grouped into 4 subscales, each representing a domain of social capital to which an individual may have access: domestic resources, personal skills, expert advice and problemsolving resources. A higher score indicates higher possibility to access to social capital.

In the telephone survey, participants' main sociodemographic and clinical data (i.e., age, gender, ethnicity, clinical diagnosis and employment status) were collected. These items were included in the analysis due to having potential impact on participant's coping strategy.

\section{Statistical analysis}

Descriptive statistics were performed in order to describe the overall sample and non-parametric tests were employed to test the association between coping strategies and experience with the TTC programme. In order to test the association between the experience with TTC programme on the 'educating' and 'challenging' coping strategies, linear regression models were employed and adjusted for: age, gender, psychiatric diagnosis, working status, ethnicity, RG-UK score, anticipated and experienced discrimination. In order to adjust for possible regional effects, NHS mental health trusts were grouped into four categories (North of England; England Midlands and East; South of England; and London) (http://www.healthcheck.nhs.uk/interactive_map) and also included in the models.
All confounders were identified a priori by previous studies (Miller \& Kaiser, 2001; Corrigan \& Watson, 2002; Mendoza-Denton et al. 2006; Ilic et al. 2012; Evans-Lacko et al. 2014a, b).

An interaction term was also added to the regression models between the time-point (each year of the Viewpoint campaign) and the exposure to the TTC programme variable, in order to identify any effect modification of the association between 'Challenging' and 'Educating' strategies.

\section{Results}

\section{Descriptive results}

During the period 2011-2014, 3903 mental health service users were interviewed. Respondents were disproportionately female $(62.2 \%, n=2430)$, with a mean (s.D.) age of 44.3 (11.4) years, and unemployment was reported by almost half of the sample $(49.3 \% ; N=$ 1922). The most commonly reported diagnoses were mood disorders (depression, $29.8 \%, n=1059$; bipolar disorder, $20.7 \%, n=734$ ), followed by schizophrenia/schizoaffective disorders $(17.2 \%, n=610)$; anxiety disorders (12.1\%, $n=431)$; personality disorders $(9.3 \%, n=329)$; and other mental disorders $(11.0 \%, n=389)$ (see Table 1$)$.

We found a slightly higher reported use of the educating strategy $(40.9 \%, n=1596)$ compared with the challenging strategy $(38.7 \%, n=1513)(p<0.001)$.

As regards service users' awareness or involvement in TTC, the proportion of people who actively participated in the campaign ranged from $2.3 \%$ in 2011 to $3.8 \%$ in 2014 . However, there was an increase in the proportion stating they had seen at least some publicity about TTC, from $17 \%$ in 2011 to $29.1 \%$ in 2014 .

As regards the challenging strategy, respondents participating in programme activities 2011-2014 reported using it more frequently than people who had never heard about TTC (57.3\% v. 37.0\%; $p<$ 0.001 ) as well as compared with people who had only seen some publicity $(57.3 \%$ v. $41.2 \%$; $p<0.001)$ (Table 2).

For the educating coping strategy, mental health users having seen some publicity of TTC reported a higher endorsement of the strategy compared with those actively involved in the campaign $(2.29 \pm 0.73 v$. $1.74 \pm 0.79, p<0.001)$. Respondents not aware of TTC also endorsed this strategy more frequently compared with people participating in some programme activities $(2.34 \pm 0.70$ v. $1.74 \pm 0.79, p<0.001)$ (Table 2).

\section{Association between TTC and coping strategies}

We found that having actively participated in the campaign activities represented a good predictor of 
Table 1. Socio-demographic characteristics of the sample of mental health users interviewed during the period 2011-2014

\begin{tabular}{|c|c|c|c|c|c|}
\hline & $\begin{array}{l}\text { Global sample } \\
\qquad N=3903\end{array}$ & $\begin{array}{c}\text { Year } \\
2011 \\
N=1014\end{array}$ & $\begin{array}{c}\text { Year } \\
2012 \\
N=1003\end{array}$ & $\begin{array}{c}\text { Year } \\
2013 \\
N=984\end{array}$ & $\begin{array}{c}\text { Year } \\
2014 \\
N=902\end{array}$ \\
\hline \multicolumn{6}{|l|}{ Experience with the TTC programme, $\%(n)^{*}$} \\
\hline Have not seen any publicity & $72.7(2823)$ & $81.0(820)$ & $72.4(723)$ & $69.4(678)$ & $67.1(602)$ \\
\hline Seen some publicities & $24.5(953)$ & $16.8(170)$ & $26.2(262)$ & $26.6(260)$ & $29.1(261)$ \\
\hline Participated in some activities & $2.8(110)$ & $2.3(23)$ & $1.4(14)$ & $4.0(39)$ & $3.8(34)$ \\
\hline \multicolumn{6}{|l|}{ Region, \% $(n)$} \\
\hline North & $40.2(1562)$ & $41.9(426)$ & $53.0(532)$ & $45.2(445)$ & $19.0(171)$ \\
\hline Midlands & $19.0(740)$ & $38.8(394)$ & 0 & $11.1(109)$ & $26.6(240)$ \\
\hline South & $24.6(957)$ & 0 & $31.2(313)$ & $27.8(274)$ & $41.6(375)$ \\
\hline London & $16.1(627)$ & $19.3(196)$ & $15.8(159)$ & $15.9(157)$ & $12.9(116)$ \\
\hline Age, mean (S.D.) & $44.3(11.4)$ & $45.0(11.2)$ & $43.7(11.2)$ & $44.5(11.3)$ & $44.0(11.9)$ \\
\hline \multicolumn{6}{|l|}{ Gender, \% $(n)$} \\
\hline Male & $37.6(1462)$ & $40.5(411)$ & $38.6(387)$ & $37.1(365)$ & $33.9(306)$ \\
\hline Female & $62.2(2416)$ & $59.3(602)$ & $61.5(617)$ & $62.5(616)$ & $66.0(595)$ \\
\hline Transgender & $0.2(7)$ & $0.2(2)$ & 0 & $0.4(4)$ & $0.1(1)$ \\
\hline Ethnicity, white, \% (n) & $90.9(3503)$ & $89.6(904)$ & $90.9(898)$ & $90.1(886)$ & $93.2(833)$ \\
\hline \multicolumn{6}{|l|}{ Employment status, \% $(n)$} \\
\hline Employed & $23.9(927)$ & $23.6(239)$ & $22.2(222)$ & $21.0(207)$ & $29.4(265)$ \\
\hline Studying/training/volunteering/other & $18.9(735)$ & $19.3(196)$ & $23.8(238)$ & $12.3(121)$ & $20.4(184)$ \\
\hline Unemployed & $49.3(1914)$ & $47.8(485)$ & $47.7(478)$ & $59.1(582)$ & 41.9 (377) \\
\hline Retired & $7.9(305)$ & $9.4(95)$ & $6.4(64)$ & $7.6(75)$ & $8.2(74)$ \\
\hline \multicolumn{6}{|l|}{ Diagnosis, \% (n) } \\
\hline Anxiety disorders & $12.1(429)$ & $9.1(82)$ & $9.4(86)$ & $14.1(130)$ & $16.5(133)$ \\
\hline Bipolar disorders & $20.7(731)$ & $20.3(184)$ & $23.8(218)$ & $19.6(181)$ & $18.7(151)$ \\
\hline Depression & $29.8(1051)$ & $34.4(311)$ & $28.0(257)$ & $28.7(625)$ & $28.0(226)$ \\
\hline Personality disorders & $9.3(328)$ & $6.1(55)$ & $7.7(71)$ & $10.6(98)$ & $13.0(105)$ \\
\hline Schizophrenia and schizoaffective disorders & $17.2(607)$ & $15.7(142)$ & $21.8(200)$ & $17.1(158)$ & $13.7(110)$ \\
\hline Other & $11.0(387)$ & $14.5(131)$ & $9.3(85)$ & $10.0(92)$ & $10.1(81)$ \\
\hline Resource Generator (RG), total score, mean (s.D.) & $13.3(6.0)$ & $13.3(6.1)$ & $13.3(6.0)$ & $12.6(5.9)$ & $14.0(6.1)$ \\
\hline RG domestic resources, mean (s.D.) & $3.9(2.0)$ & $4.0(2.0)$ & $3.8(2.0)$ & $3.7(2.0)$ & $4.0(2.0)$ \\
\hline RG expert advice, mean (s.D.) & $4.0(2.4)$ & $4.2(2.4)$ & $4.1(2.4)$ & $3.8(2.3)$ & $4.1(2.4)$ \\
\hline RG personal skills, mean (s.D.) & $2.7(1.6)$ & $2.8(1.6)$ & $2.6(1.6)$ & $2.5(1.6)$ & $2.9(1.7)$ \\
\hline RG problem solving skills, mean (S.D.) & $2.8(1.3)$ & $2.9(1.3)$ & $2.8(1.3)$ & $2.7(1.2)$ & $2.9(1.3)$ \\
\hline Anticipated discrimination, mean (S.D.) & $58.3(33.4)$ & $58.5(33.9)$ & $62.2(33.6)$ & $57.1(33.1)$ & $54.6(32.7)$ \\
\hline Experienced discrimination, mean score (s.D.) & $31.8(22.8)$ & $30.9(23.1)$ & $34.2(23.6)$ & $32.4(22.0)$ & $29.7(22.1)$ \\
\hline Challenging coping strategy, mean score (S.D.) & $2.2(0.02)$ & $2.2(1.7)$ & $2.1(1.0)$ & $2.1(1.1)$ & $2.1(1.1)$ \\
\hline Educating coping strategy, mean score (S.D.) & $2.3(0.01)$ & $2.1(0.7)$ & $2.9(0.6)$ & $2.1(0.6)$ & $2.1(0.6)$ \\
\hline
\end{tabular}

*Missing data, $N=17$.

Table 2. Coping strategies and level of experience of the TTC campaign

\begin{tabular}{llcrl}
\hline & No & Seen some publicity & Participating in some activities & $p$ \\
\hline Educating coping strategy, mean (S.D.) & $2.34(0.70)^{\mathrm{a}}$ & $2.29(0.73)^{\mathrm{b}}$ & $1.74(0.79)^{\mathrm{a}, \mathrm{b}}$ & $<0.001$ \\
Challenging coping strategy, mean (S.D.) & $2.09(1.08)^{\mathrm{a}, \mathrm{c}}$ & $2.24(1.08)^{\mathrm{b}, \mathrm{c}}$ & $2.78(1.23)^{\mathrm{a}, \mathrm{b}}$ & $<0.001$ \\
\hline
\end{tabular}

One-way ANOVA, with Bonferroni corrections.

${ }^{a}$ Having never heard about TTC $v$. Having participating in TTC, $p<0.001$.

${ }^{\mathrm{b}}$ Having seen some publicity $v$. Having participating in TTC, $p<0.001$.

${ }^{c}$ Having never heard about TTC $v$. Having seen some publicity of TTC, $p<0.001$. 
Table 3. Multivariate multiple regression models - weighted sample

\begin{tabular}{|c|c|c|}
\hline & $\begin{array}{l}\text { Educating subscale } \\
\text { Coefficient }(95 \% \mathrm{CI})\end{array}$ & $\begin{array}{l}\text { Challenging subscale } \\
\text { Coefficient }(95 \% \mathrm{CI})\end{array}$ \\
\hline \multicolumn{3}{|l|}{ Impact of TTC } \\
\hline (reference) Have not seen any publicity & - & - \\
\hline Seen some publicity & $-0.09(-0.19$ to 0.01$)$ & $0.09(-0.08$ to 0.27$)$ \\
\hline Participated in some activities & $-0.72(-0.88 \text { to }-0.55)^{*}$ & $0.74(0.29 \text { to } 1.19)^{*}$ \\
\hline \multicolumn{3}{|l|}{ Year of the campaign } \\
\hline 2011 & $-0.01(-0.10$ to 0.08$)$ & $0.04(-0.12$ to 0.20$)$ \\
\hline 2012 & $0.68(0.59 \text { to } 0.78)^{*}$ & $-0.01(-0.19$ to 0.16$)$ \\
\hline 2013 & -0.05 ( -0.13 to 0.03$)$ & 0.08 ( -0.09 to 0.25$)$ \\
\hline (reference) 2014 & - & - \\
\hline \multicolumn{3}{|l|}{ Impact of TTC ${ }^{*}$ year of the campaign } \\
\hline Seen some publicity²011 & $-0.06(-0.21$ to 0.08$)$ & $-0.07(-0.37$ to 0.22$)$ \\
\hline Seen some publicity ${ }^{*} 2012$ & $0.27(0.12 \text { to } 0.42)^{*}$ & $-0.02(-0.27$ to 0.24$)$ \\
\hline Seen some publicity*2013 & $0.04(-0.09$ to 0.17$)$ & $-0.35(-0.63 \text { to }-0.08)^{*}$ \\
\hline Participated in some activities ${ }^{*} 2011$ & $0.19(-0.22$ to 0.61$)$ & $-0.22(-1.05$ to 0.60$)$ \\
\hline Participated in some activities ${ }^{*} 2012$ & $1.29(0.93 \text { to } 1.66)^{*}$ & $-0.46(-1.08$ to 0.16$)$ \\
\hline Participated in some activities ${ }^{*} 2013$ & $0.15(-0.08$ to 0.38$)$ & $-0.26(-0.91$ to 0.38$)$ \\
\hline Clinical diagnosis, ref. Others & - & - \\
\hline Anxiety disorders & $0.05(-0.07$ to 0.16$)$ & $0.19(-0.02$ to 0.39$)$ \\
\hline Bipolar disorder & $0.01(-0.08$ to 0.10$)$ & $0.15(-0.006$ to 0.31$)$ \\
\hline Depression & $0.03(-0.06$ to 0.11$)$ & $0.20(0.04 \text { to } 0.36)^{*}$ \\
\hline Personality disorders & $-0.07(-0.18$ to 0.04$)$ & $0.23(0.04 \text { to } 0.43)^{*}$ \\
\hline Schizophrenia and schizoaffective & $0.11(0.01 \text { to } 0.22)^{*}$ & $-0.001(-0.18$ to 0.18$)$ \\
\hline RG total score & $-0.01(-0.02 \text { to }-0.01)^{*}$ & $0.02(0.02 \text { to } 0.03)^{*}$ \\
\hline DISC Total score & $-0.002(-0.003 \text { to }-0.001)^{*}$ & $0.01(0.01 \text { to } 0.02)^{*}$ \\
\hline Anticipated discrimination & $0.002(0.001 \text { to } 0.002)^{*}$ & $0.0003(-0.001$ to 0.001$)$ \\
\hline
\end{tabular}

*Significance level set at $p<0.005$, all models adjusted for region, gender age, working status, ethnicity.

Wald test, educating: impact of $\mathrm{TTC}^{*}$ year of the campaign, $p<0.001$.

Wald test, challenging: impact of TTC ${ }^{*}$ year of the campaign, $p<0.005$.

endorsing the challenging coping strategy $(\mathrm{OR}=0.74$, CI: $0.29-1.19 ; p<0.05)$, adjusted for the impact of the year of the campaign, the geographical region and for the other socio-demographic confounding variables. Moreover, just having seen some publicity had a slight positive impact on endorsement of the challenging strategy, but it did not reach the level of statistical significance (see Table 3). Interestingly, we found that each psychiatric diagnosis had a different impact on the endorsement of the challenging coping strategy. In particular, people with depressive $(\mathrm{OR}=0.20, \mathrm{CI}$ : $0.04-0.36 ; p<0.05)$ or personality disorders $(\mathrm{OR}=0.23$, CI: $0.04-0.43 ; p<0.05)$ had a slightly higher probability of adopting such a strategy. Moreover, female participants $(\mathrm{OR}=0.09, \mathrm{CI}: 0.00-0.19 ; p<0.05)$ and people with higher resources at the RG-UK scale $(\mathrm{OR}=0.02$, CI: $0.02-0.03 ; p<0.05)$ were more prone to adopt the challenging strategy. Results of the multivariate multiple regression models are shown in Table 3.

As regards the educating coping strategy, mental health users actively participating in the programme's activities scored lower on the educating coping subscale $(\mathrm{OR}=-0.72, \mathrm{CI}:-0.88$ to $-0.55 ; p<0.05)$, also adjusting for confounding variables as the year of the Viewpoint survey. The clinical diagnosis seemed to have an impact on the endorsement of educating coping strategy, and people with a diagnosis of schizophrenia/schizoaffective disorders showed a higher probability of adopting such a strategy $(\mathrm{OR}=0.1, \mathrm{CI}$ : $0.01-0.22 ; p<0.05)$. Interestingly, people reporting higher levels of anticipated discrimination were more likely to educate others on mental health topics (OR $=0.002$, CI: 0.001-0.002; $p<0.05$ ) (Table 3).

\section{Discussion}

Although there are several anti-stigma programmes ongoing in different countries, these have not to date explored the possible relationship between level of participation in such programmes and endorsement of coping strategies by service users. This study represents the first effort in Europe to test the possible role 
of an anti-stigma campaign as one of the potential predictors of mental health service users' 'challenging' and 'educating' coping strategies.

The hypothesis of the positive association between active involvements in TTC activities on two selected coping strategies was partially confirmed by our results. In particular, mental health service users actively participating in the anti-stigma project report that, they challenge stigma more than those not aware of TTC. Such a finding is consistent with the characteristics of TTC, which features contact-based activities between mental health users and members of the general population (Henderson \& Thornicroft, 2009; Henderson et al. 2013). On the other hand, longitudinal studies are needed in order to evaluate the long-term endorsement of the challenging strategy, beyond the duration of the anti-stigma campaign activity, which represents the ideal environment to apply it (Sartorius, 2010).

Moreover, possible explanatory variables having an impact on challenging coping strategy were identified, as the role of female gender and of social capital. In particular, as regards gender, our data are in line with the results of the 'Like Minds, Like Mine' programme, which found that women were more likely than men to say they had coped with stigma and discrimination (Ministry of Health, New Zealand, 2011). Moreover, we found that social capital has a positive impact on the endorsement of the challenging coping strategy. This positive impact of social capital is in line with recent studies in the field of stigma showing that social capital is related with empowerment, impacting also on self-stigma (Brohan et al. 2010, 2011; Lanfredi et al. 2015; Corker et al. 2016).

On the other hand, our results did not confirm the hypothesis that participating in the programme activities is associated with more use of the educating coping strategy. To date, the total sample of mental health users interviewed reported adopting the educating strategy more frequently than the challenging one. This general trend in the sample may have reduced the possibility to evaluate the potential predictive role of the participation in the TTC programme on the adoption of such strategy. This finding deserves further study, considering that contact-based education strategies have been found to be more effective than protest for overcoming stigma in the adult population, while for adolescents education strategy seems more effective (Corrigan et al. 2012).

Moreover, we searched for the possible explanatory role of discrimination on coping strategies. It seems that the relationship between coping strategies and anticipated discrimination is very complex, considering that Brain et al. (2014) found that anticipated discrimination was inversely associated with coping strategies. Such association was not confirmed in our study. A preliminary explanation could be due to the fact that some mental health users reporting anticipated discrimination want to take an action to prevent it, and so discrimination itself represents a good predictor for endorsing such coping strategies. Of course, this suggestion is tentative and future confirmatory studies are needed in order to disentangle and deepen the knowledge on the causal relationship between discrimination and coping responses.

Another interesting result is related to the increasing rate of mental health users stating they had 'seen some publicity from the TTC programme'. It seems that since the start of the programme, mental health services' users are becoming more aware of TTC, findings in line with figures based on the social marketing campaign of the TTC (Evans-Lacko et al. 2013).

The educating and challenging strategies were chosen as focus of the present study, as these strategies are related to the aims of the TTC programme (Henderson et al. 2013). In particular, the main feature of the TTC campaign activities was to invite people with mental disorders to participate in various sporting activity (i.e., 'Get Moving!') or in discussions on their diagnosis (e.g., 'Living Libraries') (London \& Evans-Lacko, 2010). Taking this into account, the study focussed on the possible impact of the TTC activities on these two specific coping strategies. This methodological choice also avoided further increasing the length of the interview and the participants' burden in taking part.

In the present study, a cross-sectional design was adopted. This methodological choice could have limited our findings, considering that coping strategies are the results of a dynamic process (Hinshaw, 2007). Moreover, we were not able to detect to which extent the coping strategies are directly associated with exposure to the programme. This is due to the fact that the relevant questions were added in 2011, while the survey was launched in 2008 . It could be that service users - already used to challenging stigma and educating others - were more likely to get involved in TTC. We addressed this limitation adjusting our regression analysis according to the years of the campaign and to the relevant interaction term.

Finally, a selection bias in respondents could have limited the generalisability of the present findings. It could be that those experiencing higher levels of discrimination were more likely to take part of the survey and were thus overrepresented. In fact, in our sample we found that people reporting higher levels of anticipated and experienced discrimination were more prone to adopt the challenging strategies. This could in part be due to them having more opportunities to do so.

The TTC anti-stigma programme represents one of the major efforts in England to end mental health stigma and discrimination. Evidence is encouraging on the 
positive relationship between participating in the activities of the TTC programme and using of challenging coping strategy. Such results shed light on the possible way forward in the field of fighting and overcoming stigma, although some gaps need to be filled in. To improve the research evidence base, a higher number of service users will need to be involved in the campaign activities, and the evaluation should have a longitudinal design. A possible solution could be represented by the promotion of further local activities led by service users and carers' as well as all others stakeholders' associations and by the more active involvement of mental health services (Fiorillo et al. 2013; Copeland et al. 2014; Forsman et al. 2015; Wykes et al. 2015).

\section{Acknowledgements}

We are grateful for collaboration on the evaluation by: Sue Baker, Paul Farmer, and Paul Corry. During Phase 1 of TTC GT, DR and CH were funded in relation to a National Institute for Health Research (NIHR) Applied Programme grant awarded to the South London and Maudsley NHS Foundation Trust (GT). CH, SEL and EC were supported during phases 1 and 2 by the grants to Time to Change from Big Lottery, the UK Department of Health and Comic Relief, and ER during phase 2. CH was also funded by grants from the NIHR, Maudsley Charity and Guy's and St Thomas's Charity. GT is supported by the National Institute for Health Research (NIHR) Collaboration for Leadership in Applied Health Research and Care South London at King's College London Foundation Trust. The views expressed are those of the author(s) and not necessarily those of the NHS, the NIHR or the Department of Health. GT acknowledges financial support from the Department of Health via the National Institute for Health Research (NIHR) Biomedical Research Centre and Dementia Unit awarded to South London and Maudsley NHS Foundation Trust in partnership with King's College London and King's College Hospital NHS Foundation Trust. GT is supported by the European Union Seventh Framework Programme (FP7/ 2007-2013) Emerald project.

\section{Financial Support}

The Time to Change evaluation was funded by the UK Government Department of Health, Comic Relief and Big Lottery Fund.

\section{Conflict of Interest}

None.

\section{Ethical Standard}

The authors assert that all procedures contributing to this work comply with the ethical standards of the relevant national and institutional committees on human experimentation and with the Helsinki Declaration of 1975, as revised in 2008.

\section{Availability of Data and Materials}

The DISC measure is available subject to terms and conditions at http://www.kcl.ac.uk/ioppn/depts/hspr/re search/ciemh/cmh/CMH-Measures.aspx. The Viewpoint dataset is not available. Data sharing would first require an application to the UK's Health Research Authority, which the research team does not have the capacity to do now that the Viewpoint survey has been discontinued.

\section{References}

Brain C, Sameby B, Allerby K, Quinlan P, Joas E, Lindström E, Burns T, Waern M (2014). Stigma, discrimination and medication adherence in schizophrenia: results from the Swedish COAST study. Psychiatry Research 220, 811-817.

Brohan E, Elgie R, Sartorius N, Thornicroft G, GAMIAN-Europe Study Group (2010). Self-stigma, empowerment and perceived discrimination among people with schizophrenia in 14 European countries: the GAMIAN-Europe study. Schizophrenia Research 122, 232-238.

Brohan E, Gauci D, Sartorius N, Thornicroft G, GAMIAN-Europe Study Group (2011). Self-stigma, empowerment and perceived discrimination among people with bipolar disorder or depression in 13 European countries: the GAMIAN-Europe study. Journal of Affective Disorders 129, 56-63.

Brohan E, Clement S, Rose D, Sartorius N, Slade M, Thornicroft G (2013). Development and psychometric evaluation of the Discrimination and Stigma Scale (DISC). Psychiatry Research 208, 33-40.

Copeland J, Thornicroft G, Bird V, Bowis J, Slade M (2014). Global priorities of civil society for mental health services: findings from a 53 country survey. World Psychiatry 13, 198-200.

Corker E, Hamilton S, Henderson C, Weeks C, Pinfold V, Rose D, Williams P, Flach C, Gill V, Lewis-Holmes E, Thornicroft G (2013). Experiences of discrimination among people using mental health services in England 2008-2011. British Journal of Psychiatry Supplement 55, s58-s63.

Corker E, Brown J, Henderson C (2016). How does self stigma differ across people with psychiatric diagnoses and rheumatoid arthritis, and how does it impact on self-esteem and empowerment? Psychology, Health \& Medicine 23, 1-13.

Corrigan PW, Morris SB, Michaels PJ, Rafacz JD, Rüsch N (2012). Challenging the public stigma of mental illness: a meta-analysis of outcome studies. Psychiatric Services 63, 963-973. 
Corrigan PW, Watson AC (2002). Understanding the impact of stigma on people with mental illness. World Psychiatry 1, 16-20.

Evans-Lacko S, Brohan E, Mojtabai R, Thornicroft G (2012). Association between public views of mental illness and self-stigma among individuals with mental illness in 14 European countries. Psychological Medicine 42, 1741-1752.

Evans-Lacko S, Malcolm E, West K, Rose D, London J, Rüsch N, Little K, Henderson C, Thornicroft G (2013). Influence of Time to Change's social marketing interventions on stigma in England 2009-2011. British Journal of Psychiatry Supplement 55, s77-s88.

Evans-Lacko S, Corker E, Williams P, Henderson C, Thornicroft G (2014a). Effect of the Time to Change anti-stigma campaign on trends in mental-illness-related public stigma among the English population in 2003-13: an analysis of survey data. Lancet Psychiatry 1, 121-128.

Evans-Lacko S, Courtin E, Fiorillo A, Knapp M, Luciano M, Park AL, Brunn M, Byford S, Chevreul K, Forsman AK, Gulacsi L, Haro JM, Kennelly B, Knappe S, Lai T, Lasalvia A, Miret M, O'Sullivan C, Obradors-Tarragó C, Rüsch N, Sartorius N, Svab V, van Weeghel J, Van Audenhove C, Wahlbeck K, Zlati A, ROAMER Consortium, McDaid D, Thornicroft G (2014b). The state of the art in European research on reducing social exclusion and stigma related to mental health: a systematic mapping of the literature. European Psychiatry 29, 381-389.

Farrelly S, Clement S, Gabbidon J, Jeffery D, Dockery L, Lassman F, Brohan E, Henderson RC, Williams P, Howard LM, Thornicroft G, MIRIAD study group (2014). Anticipated and experienced discrimination amongst people with schizophrenia, bipolar disorder and major depressive disorder: a cross sectional study. BMC Psychiatry 29, 157.

Farrelly S, Jeffery D, Rüsch N, Williams P, Thornicroft G, Clement S (2015). The link between mental health-related discrimination and suicidality: service user perspectives. Psychological Medicine 13, 1-10.

Fiorillo A, Luciano M, Del Vecchio V, Sampogna G, Obradors-Tarragó C, Maj M, ROAMER Consortium (2013). Priorities for mental health research in Europe: a survey among national stakeholders' associations within the ROAMER project. World Psychiatry 12, 165-170.

Forsman AK, Wahlbeck K, Aarø LE, Alonso J, Barry MM, Brunn M, Cardoso G, Cattan M, de Girolamo G, Eberhard-Gran M, Evans-Lacko S, Fiorillo A, Hansson L, Haro JM, Hazo JB, Hegerl U, Katschnig H, Knappe S, Luciano M, Miret M, Nordentoft M, Obradors-Tarragó C, Pilgrim D, Ruud T, Salize HJ, Stewart-Brown SL, Tómasson K, van der Feltz-Cornelis CM, Ventus DB, Vuori J, Värnik A, ROAMER Consortium (2015). Research priorities for public mental health in Europe: recommendations of the ROAMER project. European Journal of Public Health 25, 249-254.

Friedrich B, Evans-Lacko S, London J, Rhydderch D, Henderson C, Thornicroft G (2013). Anti-stigma training for medical students: the Education Not Discrimination project. British Journal of Psychiatry 202, s89-s94.

Gaebel W, Zäske H, Baumann AE, Klosterkötter J, Maier W, Decker P, Möller HJ (2008). Evaluation of the German
WPA "program against stigma and discrimination because of schizophrenia-Open the Doors": results from representative telephone surveys before and after three years of antistigma interventions. Schizophrenia Research 98, 184-193.

Griffiths KM, Carron-Arthur B, Parsons A, Reid R (2014). Effectiveness of programs for reducing the stigma associated with mental disorders. A meta-analysis of randomized controlled trials. World Psychiatry 13, 161-175.

Hamilton S, Pinfold V, Rose D, Henderson C, Lewis-Holmes E, Flach C, Thornicroft G (2011). The effect of disclosure of mental illness by interviewers on reports of discrimination experienced by service users: a randomised study. International Review of Psychiatry 23, $47-54$.

Heinz A, Charlet K, Rapp MA (2015). Public mental health: a call to action. World Psychiatry 14, 49-50.

Henderson C, Thornicroft G (2009). Stigma and discrimination in mental illness: Time to Change. Lancet 373, 1928-1930.

Henderson C, Corker E, Lewis-Holmes E, Hamilton S, Flach C, Rose D, Williams P, Pinfold V, Thornicroft G (2012). England's time to change antistigma campaign: one-year outcomes of service user-rated experiences of discrimination. Psychiatric Services 63, 451-457.

Henderson C, Evans-Lacko S, Thornicroft G (2013). Mental illness stigma, help seeking, and public health programs. American Journal of Public Health 103, 777-780.

Henderson RC, Corker E, Hamilton S, Williams P, Pinfold V, Rose D, Webber M, Evans-Lacko S, Thornicroft G (2014). Viewpoint survey of mental health service users' experiences of discrimination in England 2008-2012. Social Psychiatry and Psychiatric Epidemiology 49, 1599-1608.

Hinshaw SP (2007). The Mark of Shame: Stigma of Mental Illness and an Agenda for Change. Oxford University Press: Oxford.

Ilic M, Reinecke J, Bohner G, Röttgers HO, Beblo T, Driessen M, Frommberger U, Corrigan PW (2012). Protecting self-esteem from stigma: a test of different strategies for coping with the stigma of mental illness. International Journal of Social Psychiatry 58, 246-257.

Lanfredi M, Zoppei S, Ferrari C, Bonetto C, Van Bortel T, Thornicroft G, Knifton L, Quinn N, Rossi G, Lasalvia A, The ASPEN Study group (2015). Self-stigma as a mediator between social capital and empowerment among people with major depressive disorder in Europe: the ASPEN study. European Psychiatry 30, 58-64.

Link BG, Mirotznik J, Cullen FT (1991). The effectiveness of stigma coping orientations: can negative consequences of mental illness labelling be avoided? Journal of Health and Social Behavior 32, 302-320.

Link BG, Struening EL, Neese-Todd S, Asmussen S, Phelan JC (2001). Stigma as a barrier to recovery: the consequences of stigma for the self-esteem of people with mental illnesses. Psychiatric Services 52, 1621-1626.

Link BG, Struening EL, Neese-todd S, Asmussen S, Phelan JC (2002). On describing and seeking to change the experience of stigma. Psychiatric Rehabilitation Skills 6, 201-231.

Link BG, Phelan JC, Hatzenbuehler ML (2014). Stigma and social inequality. In Handbook of the Social Psychology of 
Inequality (ed. J McLeod, E Lawler and M Schwalbe), pp. 49-64. Springer: New York.

London J, Evans-Lacko S (2010). Challenging mental health-related stigma through social contact. European Journal of Public Health 1, 1-2.

Major B, Townsend SSM (2010). Coping with bias. In The SAGE Handbook of Prejudice, Stereotyping and Discrimination (ed. JF Dovidio, M Hewstone, P Glick and VM Esses), pp. 410-425. SAGE Publications Ltd: London.

Mehta N, Clement S, Marcus E, Stona AC, Bezborodovs N, Evans-Lacko S, Palacios J, Docherty M, Barley E, Rose D, Koschorke M, Shidhaye R, Henderson C, Thornicroft G (2015). Evidence for effective interventions to reduce mental health-related stigma and discrimination in the medium and long term: systematic review. British Journal of Psychiatry 207, 377-384.

Mendoza-Denton R, Page-Gould E, Pietrzak J (2006). Mechanisms for coping with status-based rejection expectations. In Stigma and Group Inequality: Social Psychological Approaches (ed. S Levin and C van Laar), pp. 151-169. Erlbaum: Mahwah, NJ.

Miller CT, Kaiser CR (2001). A theoretical perspective on coping with stigma. Journal of Social Issues 57, 73-92.

Ministry of Health, New Zealand (2011). Research Report for Ministry of Health. Discrimination Reported By Users Of Mental Health Services: 2010 Survey. New Zealand.

Moses T (2015). Coping strategies and self-stigma among adolescents discharged from psychiatric hospitalization: a 6-month follow-up study. International Journal of Social Psychiatry 61, 188-197.

NHS Scotland (2008). Stigma: A Guidebook for Action. http:// ec.europa.eu/health/mental_health/eu_compass/policy_ recommendations_declarations/stigma_guidebook.pdf.

Rüsch N, Angermeyer MC, Corrigan PW (2005). Mental illness stigma: concepts, consequences, and initiatives to reduce stigma. European Psychiatry 20, 529-539.

Sartorius N (2010). Short-lived campaigns are not enough. Nature 468, 163-165.

Sartorius N (2014). Opening minds in Canada. Canadian Journal of Psychiatry 59, S4-S5.

Sibitz I, Amering M, Unger A, Seyringer ME, Bachmann A, Schrank B, Benesch T, Schulze B, Woppmann A (2011).

The impact of the social network, stigma and empowerment on the quality of life in patients with schizophrenia. European Psychiatry 26, 28-33.
Stuart H, Arboleda-Florez J, Sartorius N (2012). Paradigms Lost: Fighting Stigma and the Lessons Learned. Oxford University Press: Oxford.

Stuart H, Chen SP, Christie R, Dobson K, Kirsh B, Knaak S, Koller M, Krupa T, Lauria-Horner B, Luong D, Modgill G, Patten SB, Pietrus M, Szeto A, Whitley R (2014). Opening minds in Canada: background and rationale. Canadian Journal of Psychiatry 59, S8-S12.

Thornicroft C, Wyllie A, Thornicroft G, Mehta N (2014). Impact of the "Like Minds, Like Mine" anti-stigma and discrimination campaign in New Zealand on anticipated and experienced discrimination. Australian New Zealand Journal of Psychiatry 48, 360-370.

Thornicroft G, Brohan E, Kassam A, Lewis-Holmes E (2008). Reducing stigma and discrimination: candidate interventions. International Journal of Mental Health Systems 2, 3.

Thornicroft G, Mehta N, Clement S, Evans-Lacko S, Doherty M, Rose D, Koschorke M, Shidhaye R, O'Reilly C, Henderson C (2015). Evidence for effective interventions to reduce mental-health-related stigma and discrimination. Lancet [Epub ahead of print].

Vaughan G, Hansen C (2004). "Like Minds, Like Mine": a New Zealand project to counter the stigma and discrimination associated with mental illness. Australian Psychiatry 12, 113-117.

Wahlbeck K (2015). Public mental health: the time is ripe for translation of evidence into practice. World Psychiatry 14, 36-42.

Webber MP, Huxley PJ (2007). Measuring access to social capital: the validity and reliability of the Resource Generator-UK and its association with common mental disorder. Social Science \& Medicine 65, 481-492.

Weissman MM (2015). Applied public mental health: bridging the gap between evidence and clinical practice. World Psychiatry 14, 45-47.

Wykes T, Haro JM, Belli SR, Obradors-Tarragó C, Arango C, Ayuso-Mateos JL, Bitter I, Brunn M, Chevreul K, Demotes-Mainard J, Elfeddali I, Evans-Lacko S, Fiorillo A, Forsman AK, Hazo JB, Kuepper R, Knappe S, Leboyer M, Lewis SW, Linszen D, Luciano M, Maj M, McDaid D, Miret M, Papp S, Park AL, Schumann G, Thornicroft G, van der Feltz-Cornelis C, van Os J, Wahlbeck K, Walker-Tilley T, Wittchen HU, ROAMER consortium (2015). Mental health research priorities for Europe. Lancet Psychiatry 2, 1036-1042. 